\title{
IDEA: Electronic Writing in L2: Accuracy vs Other Outcomes
}

\author{
Luisa Pérez-Sotelo \\ Emporia State University \\ and \\ Manuela González-Bueno \\ University of Kansas
}

\begin{abstract}
This article describes the effects of dialogue journaling through e-mail on the language produced by two groups (experimental and control) of first-semester-Spanish college students. The independent variable was the use of electronic mail while the dependent variables were accuracy and number of words per message. Quantitative results showed that the control group significantly outperformed the experimental group regarding grammatical accuracy. Nonsignificant differences for either lexical accuracy or number of words were found. For qualitative analysis, a questionnaire administered to both groups requested their opinions on the effectiveness and attitude towards the journaling technique. The authors concluded that, although the e-mail medium promoted a more positive attitude towards the language, dialogue journals via e-mail did not improve grammar skills. Thus, suggestions are offered to modify instruction to enhance other positive results from the use of electronic writing in L2, thereby providing a way to incorporate authentic, real-life writing tasks, develop better classroom rapport, and allow advantages to students otherwise reluctant to speak in class.
\end{abstract}

Key Words: Writing, e-mail, dialogue journals, accuracy, productivity, Spanish, language attitude, teacher-student rapport

$\mathrm{I}^{\mathrm{n}}$

nterest in the effects of computer-mediated communication (CMC) on language learning, both synchronous (chat-rooms) and asynchronous (electronic mail), has increased in recent years and has been the focus of a growing number of language studies. Some specific advantages of foreign-language learning generated via CMC identified in those studies are: the use of more language functions, more effective discourse management, more language productivity, greater levels of participation (González-Bueno and Pérez 2000; González-Bueno 1998; St. John and Cash 1995; Van Handle and Corl 1998; Wang 1994), and a non-threatening interaction environment (Beauvois 1996). Also, easy manipulation of the text while editing allows greater ease in the writing process.

Using electronic mail to communicate in a foreign language seems therefore to put learners in a position of greater control over their own learning since they can determine the level, quality, and amount of their own participation (Roche-Dolan 1999). In addition, Beauvois (1998) asserts that "reading vast amounts of input from classmates and from the instructor also contributes to more contact with the target language than is possible in the traditional classroom" (180), where teacher talking occurs most of the time. E-mail has mediated the delivery of instruction and enhanced communication between teachers and their students (Cooper and Selfe 1990; Fred and Roberts 1991). In other words, learners cannot simply listen to or read input: they must be active conversational participants by interacting and negotiating the type of input they receive. CMC intensifies this interaction.

By incorporating CMC in foreign-language classrooms as an additional tool, instructors can also contribute to achieving the goal areas of the National Standards for Foreign Language

Pérez-Sotelo, Luisa, and Manuela Gonzälez-Bueno "IDEA: Electronic Writing in L2: Accuracy vs Other Outcomes" Hispania 86.4 (2003): 869-873 
Learning: Communication, Cultures, Connections, Comparisons, and Communities (Standards Collaborative 1999). Specifically, learners develop linguistic awareness in both their native and target languages (Blake 2000; Roche-Dolan 1999), which addresses the "Comparison" goal while maintaining the main focus of the lesson. Also, using CMC helps extend students' roles as classroom learners into a wider perspective as world communicators (González-Bueno 1998), which addresses the "Communities" goal. Instructors who incorporate CMC into their teaching are satisfying the following National Educational Technology Standards for Teachers (ISTE 2000b):

1. Teachers plan and design effective learning environments and experiences supported by technology.

2. Teachers implement curriculum plans that include methods and strategies for applying technology to maximize student learning.

3. Teachers use technology resources to collect and analyze data, interpret results, and communicate findings to improve instructional practice and maximize student learning. (9)

Further, as the National Educational Technology Standards for Students (ISTE 2000a) point out, "today's students communicate instantly through e-mail and receive prompt feedback on how well their messages are understood" (76). This immediate feedback can positively impact learners' self-monitoring skills by offering not only content feedback, but also a model of correct usage.

Hence, the foreign-language teaching community has broadly accepted the use of electronic writing as a beneficial tool for improving writing skills. To date, however, most studies have focused on an analysis of discourse and content-oriented components of writing proficiency (Murray 1988; Zuboff 1988; Ferrara, Brunner and Whittenmore 1991), but few have looked at the development of more formal writing components, such as grammatical and lexical accuracy. Even among those, there does not seem to be agreement concerning the benefits of CMC in developing grammatical accuracy. Blake (2000), for instance, states, "frequent incidental lexical negotiations, in contrast to the paucity of syntactic negotiations, might stimulate vocabulary development, whereas it leaves unanswered or unsatisfactorily addressed the issue of grammatical development" (120). Along the same lines, Kern (1998) affirmed that "computers are now most often used as a medium for quick, casual communication, in which formal accuracy is of secondary importance" (83). On the other hand, Salaberry (2000) argued that the functional communication constraints (i.e., reduced means of expression) represented in e-mail communication may force learners to focus on the morphological features of L2 grammars more than they would in other communication settings, such as face-to-face contacts.

In their comparison between electronic and traditional dialogue journaling, González-Bueno and Pérez (2000) did not consider the effect of the experimental group (out-of-class, e-mail) having more time to write than the control group (in-class, paper-and-pencil). If the control group had been given as much time as the experimental group, the electronic version might not have proven more beneficial in amount of language than paper-and-pencil. Thus, the question still remains: Is $\mathrm{CMC}$ going to help foreign-language learners improve formal aspects of writing?

The current study eliminated the time constraints from the control group by making the dialogue journal an out-of-class assignment (therefore isolating the communication medium email versus paper-and-pencil as the only independent variable). Moreover, the authors considered that the tool for analysis employed in González-Bueno and Pérez (2000) was too comprehensive and captured grammatical errors that learners could not have avoided in view of their limited proficiency. Focusing on fewer, more common grammatical errors presumably would provide a more accurate picture of the effectiveness of the technique. As a result, the present study differed from the earlier in the following respects: (a) time constraints were eliminated from the comparison group by making the dialogue journal an out-of-class assignment, and (b) the target of the grammar analysis was limited to subject-verb agreement, noun-adjective agreement, and the expression of possession with "de." These were the three most common mistakes previously observed by González-Bueno and Pérez (2000) in their study. Although 
these aspects of Spanish grammar are not necessarily fully controlled in the early stages of acquisition (Lee and VanPatten 1995), they are nevertheless presented early in the syllabus followed by the instructor. The researchers operate under the assumption that the written format in general, and the electronic medium in particular, might encourage the use of the monitor (Krashen 1982), thereby allowing for greater control of these features than students would be able to show in an oral situation (spontaneous speech).

The researchers of this study measured lexical accuracy in the same way González-Bueno and Pérez (2000) did, that is, by looking at the appropriateness of the chosen word in the given context. For example, the use of "primavera roto" rather than "vacaciones de primavera" for "Spring break" was considered a vocabulary error.

The following three research questions guided the study:

1. What is the effect of using electronic mail on the quantity of Spanish written language generated by the experimental group as compared to the control group?

2. What is the effect of using electronic mail on the lexical accuracy of Spanish written language generated by the experimental group as compared to the control group?

3. What is the effect of using electronic mail on the grammatical accuracy of Spanish written language generated by the experimental group as compared to the control group?

The method consisted of using dialogue journals as weekly assignments during one semester (16 weeks) via paper and pencil in the control group, and e-mail in the experimental group. Students in both groups wrote messages on topics of their choice (following traditional dialogue journal techniques). Subjects were allowed to consult their textbook, Temas (Cubillos, 2000), dictionaries, more advanced students, native speakers, or their instructor as information sources. The instructor of both groups, one of the researchers, responded to each message by making comments on content rather than on form. Care was taken that comments comparable in length, quality of language, and amount of indirect feedback were offered to both groups equally. Also, to avoid researchers' bias effect, both researchers graded dialogue journals in both groups. In addition, by providing comprehensible input as she responded to her students' messages, the instructor also offered implicit correction in the form of paraphrasing. The instructor's responses acted as models of accurate language, so grammatical corrective feedback was provided automatically. This implicit form of correction has been found to have a positive effect on second-language writing (Semke 1984). Grammatical accuracy could then be overtly addressed in form-focused regular writing assignments, allowing dialogue journals to be a less structured activity.' Both experimental and control groups wrote their messages out of class. When dialogue journals are handled outof-class, students are not tied up with time and space limitations, constraints of the class session.

Members of the experimental and control groups completed a questionnaire at the end of the semester that sought their opinions on the effectiveness of the journaling technique (e-mail or paper-and-pencil) and the attitude toward the language they were studying.

Based on the present study, the following conclusions may be drawn:

1. According to the statistical analysis, the paper-and-pencil technique was significantly more beneficial than e-mail in terms of grammatical accuracy.

2. The paper-and-pencil and the e-mail versions of dialogue journals were not significantly different in terms of lexical accuracy and amount of language generated.

As suggested by other studies, e-mail offers obvious advantages over paper-and-pencil techniques in terms of convenience, flexibility, language productivity, and time management (González-Bueno 1998; Roche-Dolan 1999; St. John and Cash 1995; Wang 1994). The present study, however, suggests that e-mail offers no advantages over paper-and-pencil in terms of grammatical or lexical accuracy. Nevertheless, the study was suggestive of other advantages or benefits of the use of electronic writing as a pedagogical tool in L2. 
It is noteworthy that dialogue journaling in foreign-language writing offered particular advantages to students who were reluctant to speak up in the classroom. Students were able to tell their instructor about their likes, dislikes, concerns, and about their personal life in general because of its open-ended feature. Students wrote to their instructor on topics they would never have broached during class activities. Furthermore, students did not feel intimidated because journals were not traditionally graded, and yet received corrective feedback as the instructor modeled responses. Just as importantly, better classroom rapport can be developed with this technique, either via e-mail or traditional paper-and-pencil. However, in order to observe any significant advantages of the electronic media over the more traditional paper-and-pencil means, we may have to examine more discourse-oriented features of the writing process in the context of higher-level courses, given that the focus upon beginners imposes constrictive parameters on writing potential.

\section{Implications for Teaching}

Foreign-language teachers should focus on the content and design of learning materials before selecting the means of delivery (Kaufman, 1998). The results of this study imply that email does not appear to provide significant advantages to the writing task regarding amount and accuracy of language generated by beginning students. Therefore, electronic writing should be used not specifically as a means of improving writing samples but as an additional way to incorporate authentic, real-life writing tasks into the foreign-language classroom, with more realistic expectations in terms of the development of formal aspects of writing. Following earlier calls for caution towards the electronic revolution (Kupisiewicz 1985; Moll 1999), this study supports the use of electronic mail only as a supplement to existing modes of teaching L2 writing. However, one way to increase accuracy might be by modifying instruction inherent to dialogue journals, that is, by making dialogue journals a more form-focused activity. This could be done in various ways:

a) Instructors should make a conscious effort to identify and paraphrase students' errors in their responses.

b) Students should be made aware of this form of indirect correction so they can pay attention to instructors' responses and look for specific paraphrasing patterns.

c) Students would be expected to avoid repeating reccurring mistakes that have already been corrected.

Overall, the authors recommend the use of e-mail dialogue journals because they appear to motivate students, both to write more and to use topics not constrained to classroom vocabulary. According to a students' survey, e-mail dialogue journaling is a "fun" assignment that teaches more about computers, thus preparing them better for their future professions. This technique is very useful and convenient for non-traditional students and for those who live over 25 miles away from college and/or work because they don't have to go to school on a dialogue journal-day. With this tool, students can e-mail their instructor at any time of day or night, thus avoiding unnecessary traveling, postage fees or a long-distance phone call in many instances. Finally, e-mail journals could be more successful if, instead of expecting writing accuracy, teachers would focus on language functions, variety of topics used by students, socio-linguistic features and monitor techniques. Electronic dialogue journals might in the long term also result in accuracy improvement if the suggestions above are implemented.

\section{NOTE}

\footnotetext{
'See González-Bueno (1998) and González-Bueno and Përez (2000) for a complete literature review on electronic dialogue journals.
} 


\section{WORKS CITED}

Beauvois, M. 1996. "Computer Mediated Communication (CMC): A Link to Improve Communication and Oral Skills in Second Language Learning." Michael Bush, Ed. Technology-Enhanced Language Learning The ACTFL Volume on Technology. Lincolnwood, IL: National Textbook. 165-84.

- 1998. "Write to Speak: The Effects of Electronic Communication on the Oral Achievement of Fourth-Semester French Students." J. A. Muykens, Ed. New Ways of Learning and Teaching: Focus on Technology and Foreign Language Education. Boston, MA: Heinle \& Heinle. 165-83.

Blake, R. 2000. "Computer Mediated Communication: A Window on L2 Spanish Interlanguage." Language Learning \& Technology 4.1: 120-36.

Cooper, M. M., and C. L. Selfe. 1990. "Computer Conferences and Learning: Authority, Resistance, and Internally Persuasive Discourse." College English 52: 847-69.

Cubillos, J. H. 2000. Temas. Boston, MA: Heinle \& Heinle.

Ferrara, K., H. Brunner, and G. Whittenmore. 1991. "Interactive Written Discourse as an Emergent Register." Written Communication 8: 8-34.

Fred, P. and J. Roberts. 1991. "Pen-Pals in Science: Electronic Mail, Mentor Teams, Hands-on Activities, Small Groups of Children." Paper presented at the annual meeting of the American Educational Research Association, Chicago, IL.

González-Bueno, M. 1998. "The Effect of Electronic Mail on Spanish L2 Discourse." Language Learning and Technology 1.2: 55-70.

González-Bueno, M. and L. Pérez. 2000. "Electronic Mail in Foreign Language Writing: A Study of Grammatical and Lexical Accuracy, and Quantity of Language." Foreign Language Annals 33.2: 189-98.

International Society for Technology in Education. 2000a. National Educational Technology Standards for Students: Connecting Curriculum and Technology. Eugene, OR: ISTE and USDE.

International Society for Technology in Education. 2000b. National Educational Technology Standards for Teachers. Eugene, OR: ISTE NETS Projects.

Kaufman, R. 1998. "The Internet as the Ultimate Technology and Panacea." Educational Technology 38.1: 63-64.

Kern, R. 1998. "Technology, Social Interaction, and FL Literacy." Judith A. Muykens, Ed. New Ways of Learning and Teaching: Focus on Technology and Foreign Language Education. Boston, MA: Heinle \& Heinle. 57-92.

Krashen, S. 1982. Principles and Practice in Second Language Acquisition. New York: Pergamon.

Kupisiewicz, C. 1985. "Second Reply: The Media in Education: 'Panacea' or Simple Teachers' Aids (sic)." Prospects: Quarterly Review of Education 15.4: 515-19.

Lee, J. and B. VanPatten. 1995. Making Communicative Language Teaching Happen. New York: McGraw-Hill.

Moll, M. 1999. "Calling for Time Out: Education in the Fast Lane of Technological Change." Education Canada 39.2: 30-33.

Murray, D. 1988. "Computer-Mediated Communication: Implications for ESP." English for Special Purposes 7: 3-18.

Roche-Dolan, M. 1999. "Las cinco ces con el correo electrónico." Paper presented at the $33^{\text {rd }}$ Annual Meeting of ACTFL, Dallas, TX.

Salaberry, R. 2000. "Pedagogical Design of Computer Mediated Communication Tasks: Learning Objectives and Technological Capabilities." Modern Language Journal 84.1: 28-37.

Semke, H. 1984. "Effects of the Red Pen." Foreign Language Annals 17.3: 195-202.

Standards Collaborative. 1999. Standards for Foreign Language Learning in the 21" Century. Lawrence, KS: Allen Press.

St. John, E. and D. Cash. 1995. "Language Learning via E-mail: Demonstrable Success with German." M. Warschauer, Ed. Virtual Connections: Online Activities and Projects for Networking Language Learners. Honolulu, HI: University of Hawaii, Second Language Teaching \& Curriculum Center. 191-97.

Van Handle, D. C. and K. A. Corl. 1998. "Extending the Dialogue: Using Electronic Mail and the Internet to Promote Conversation and Writing in Intermediate Level German Language Courses." CALICO Journal 15. 1-3, $129-42$.

Wang, Y. 1994. E-mail dialogue journaling in an ESL reading and writing classroom (Doctoral Dissertation, University of Oregon, 1993). Dissertation Abstracts International 54: 3316.

Zuboff, S. 1988. In the Age of the Smart Machine. New York: Basic Books. 